\title{
A rare $K I F 5 B-A L K$ fusion variant in a lung adenocarcinoma patient who responded to crizotinib and acquired the ALK L1196M mutation after resistance: a case report
}

\author{
Hao Zeng ${ }^{1}$, Yujie Liu ${ }^{1}$, Weiya Wang ${ }^{2}$, Yuan Tang ${ }^{2}$, Panwen Tian ${ }^{3}$, Weimin $\mathrm{Li}^{4}$ \\ ${ }^{1}$ Department of Respiratory and Critical Care Medicine, West China Hospital, West China School of Medicine, Sichuan University, Chengdu, \\ China; ${ }^{2}$ Department of Pathology, West China Hospital, Sichuan University, Chengdu, China; ${ }^{3}$ Department of Respiratory and Critical Care \\ Medicine, Lung Cancer Treatment Center, West China Hospital, Sichuan University, Chengdu, China; ${ }^{4}$ Department of Respiratory and Critical \\ Care Medicine, West China Hospital, Sichuan University, Chengdu, China \\ Correspondence to: Panwen Tian. Department of Respiratory and Critical Care Medicine, Lung Cancer Treatment Center, West China Hospital, No. \\ 37 Guo Xue Alley, Chengdu 610041, China. Email: mrascend@163.com.
}

\begin{abstract}
An increasing number of anaplastic lymphoma kinase $(A L K)$ gene fusion variants have been reported with the popularity of next-generation sequencing (NGS), such as striatin gene (STRN)-ALK, EMAP like 4 (EML4)-ALK and S1 RNA binding domain 1 (SRBD1)-ALK. The clinical outcomes of nonsmall cell lung cancer (NSCLC) patients improved dramatically with the treatment of tyrosine kinase inhibitors (TKIs), but responses to ALK-TKIs differ even for the same fusion variants with different breakpoints. The clinical effectiveness of ALK-TKIs on a new fusion variant needs to be evaluated. Here, we report a case of a lung adenocarcinoma patient, a 70-year-old nonsmoking Chinese man, with rare $A L K$ rearrangement form of, namely, a kinesin family member 5B (KIF5B)-ALK (K20:A20) fusion which was identified in tissue by capture-based NGS. The patient achieved a partial response (PR) after treatment with crizotinib. Additionally, an $A L K$ L1196M mutation was detected when the disease progressed after 11 months and was indicated to be sensitive to ceritinib. As far as we know, this is the first report showing that $K I F 5 B-A L K(\mathrm{~K} 20: \mathrm{A} 20)$ is a fusion variant that is sensitive to crizotinib. We provided a treatment strategy for managing NSCLC patients with $K I F 5 B-A L K$ (K20:A20) fusion or ALK L1196M mutation after crizotinib resistance. Additionally, dynamic genomic analysis of ALK-TKIs treatments is important.
\end{abstract}

Keywords: Anaplastic lymphoma kinase fusion ( $A L K$ fusion); resistance mechanisms; targeted therapy; non-small cell lung cancer (NSCLC); next-generation sequencing (NGS)

Submitted Oct 21, 2020. Accepted for publication Feb 03, 2021.

doi: 10.21037/apm-20-2081

View this article at: http://dx.doi.org/10.21037/apm-20-2081

\section{Introduction}

Anaplastic lymphoma kinase $(A L K)$ receptor tyrosine kinase gene rearrangement is a common driving oncogene for patients with non-small cell lung cancer (NSCLC), accounting for approximately $5 \%$ of all NSCLC patients (1). In addition to echinoderm microtubuleassociated protein-like 4 (EML4) gene, the most prevalent partner for $A L K$ in NSCLC, approximately 10 other partners have been reported $(2,3)$. Located on the short arm of human chromosome 10 and encoding member $5 \mathrm{~B}$ of the kinesin family of proteins, $K I F 5 B$ is a rare partner for $A L K$, and exons 1 to 24 fused to exon 20 of $A L K$, generating a fusion protein (4). Although $K I F 5 B-A L K$ fusion genes with different breakpoints have been reported in several lung cancer cases, only one study reported the efficiency of crizotinib in a case of large-cell neuroendocrine carcinoma (LCNEC) with KIF5B exon 17 to $A L K$ exon 20 (5). Furthermore, different $A L K$ fusions, even the same fusion with different breakpoints, exhibit different responses to ALK-TKIs. For example, different $E M L 4-A L K$ variants 
exhibited differential responses to crizotinib (6). However, the responses of $K I F 5 B-A L K$ gene fusions with different breakpoints to crizotinib remain unknown.

Both alectinib and crizotinib were recommended as category 1 agents for first-line therapy in patients with $A L K$-positive NSCLC in the National Comprehensive Cancer Network (NCCN) guidelines, version 5. 2018 (7), but alectinib is preferred. However, given its high cost, alectinib is unlikely to be cost-effective for populations in China (8). Crizotinib, a selective ATP-competitive inhibitor of ALK, is an inhibitor of ALK phosphorylation and signal transduction, leading to G1-S phase cell cycle arrest and

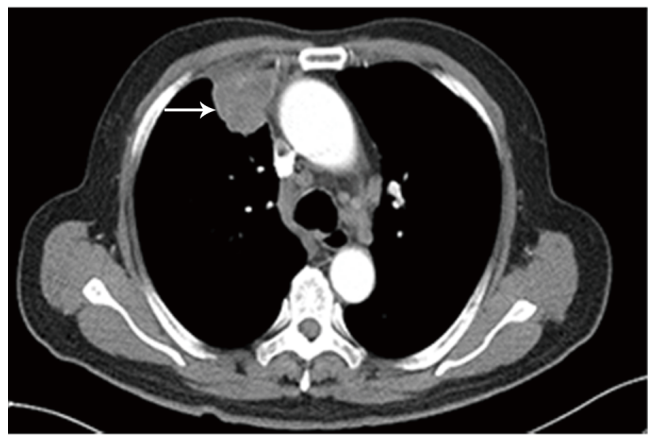

Figure 1 Computed tomography (CT) scan of the thorax before treatment. Lung adenocarcinoma in the upper lobe of the right lung (white arrow) revealed by radiologic. inducing apoptosis in NSCLC patients harboring an $A L K$ translocation $(9,10)$.

Herein, we first reported a rare KIF5B-ALK (K20:A20) fusion variant in a lung adenocarcinoma that responded well to crizotinib. The $A L K$ L1196M mutation was identified in the setting of crizotinib resistance. Finally, we revealed that ceritinib potently overcomes the $A L K$ L1196M mutation, and liquid biopsy is an available method to assess molecular changes after resistance and guide treatment strategies. We present the following case in accordance with the CARE reporting checklist (available at http://dx.doi.org/10.21037/ apm-20-2081) (11).

\section{Case presentation}

A 70-year-old nonsmoking Chinese man, with a negative family history of genetic disease, presented to our hospital with a 3 -month history of cough and expectoration. On March 22, 2018, a computed tomography (CT) scan revealed a $4.2 \mathrm{~cm} \times 4.1 \mathrm{~cm}$ mass in the upper lobe of the right lung (Figure 1) with liver and bone metastasis. Transthoracic needle biopsy established the pathologic diagnosis of lung adenocarcinoma (T4N3M1c, stage IVB). KIF5B-ALK (K20:A20) fusion was identified in tissue by capture-based next-generation sequencing (NGS), and the tumor was positive for ALK-Ventana by immunohistochemistry staining (Figure 2).

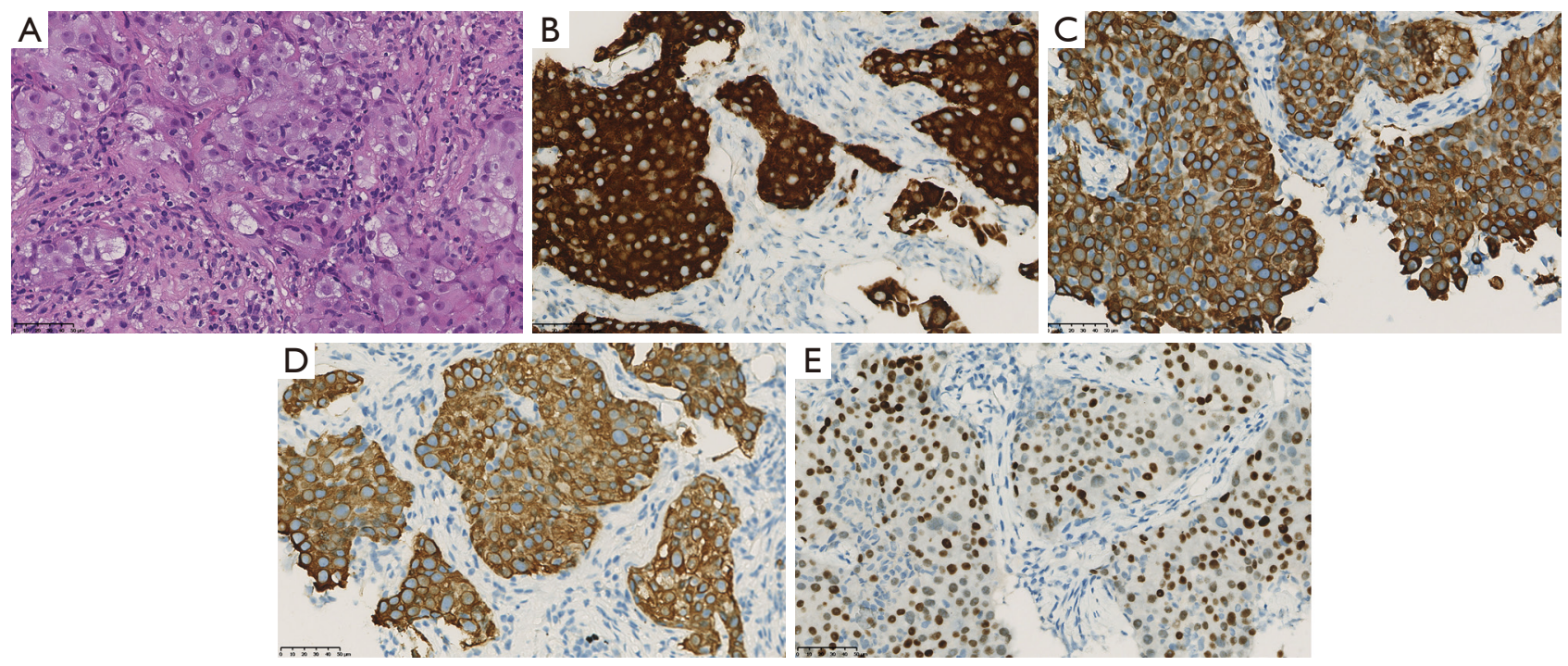

Figure 2 Histological findings (40× magnification). (A) Hematoxylin and eosin-stained biopsy specimen reveals adenocarcinoma; (B) immunohistochemical analysis showing anaplastic lymphoma kinase (ALK)-positive staining; (C) keratin 7 (CK7)-positive staining; (D) pancytokeratin (PCK)-positive staining; (E) thyroid transcription factor-1 (TTF-1)-positive staining. Scale bars represent $50 \mu \mathrm{m}$. 

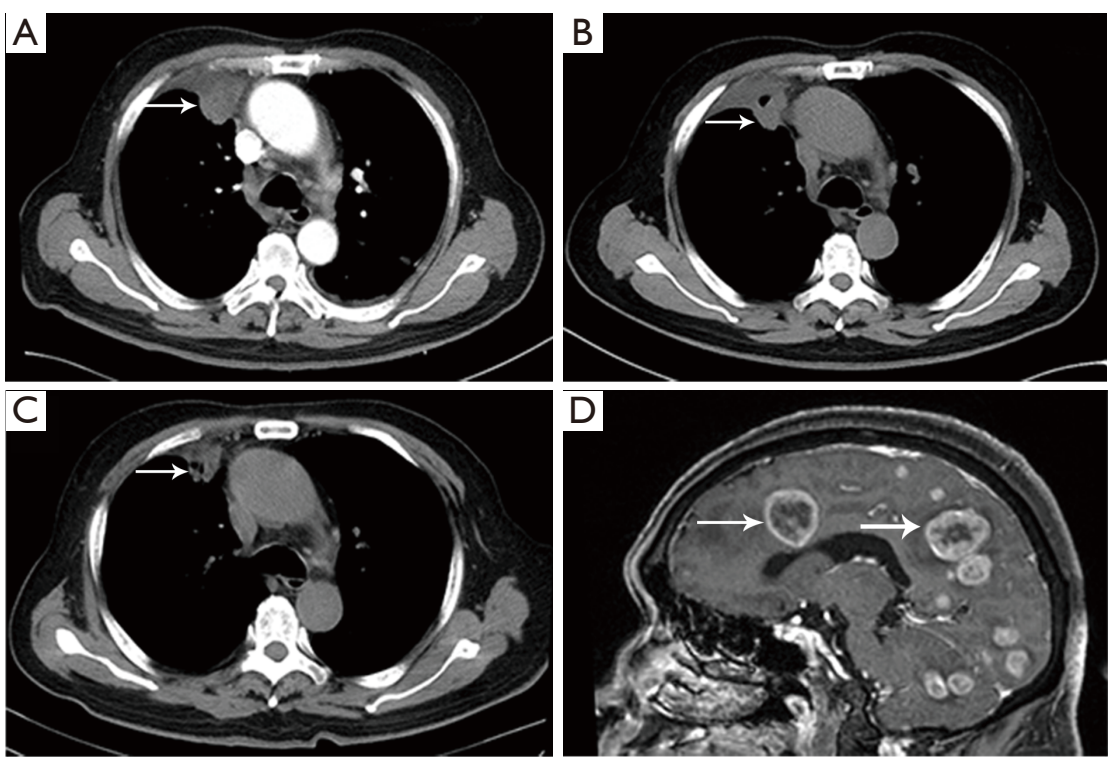

Figure 3 Dynamic computed tomography (CT) scan of lung masses and brain lesions revealed by magnetic resonance imaging (MRI) scan (white arrow). (A,B,C) CT scan of lung masses after 2, 6 and 11 months of crizotinib therapy. (D) MRI scan of the brain revealed intracranial progression after crizotinib resistance $(3.0 \mathrm{~cm} \times 2.5 \mathrm{~cm})$.

The patient was administered a first-generation tyrosine-kinase inhibitor targeting $A L K$, crizotinib (250 mg twice daily), beginning on April 18, 2018. The disease achieved a partial response (PR) (Figure $3 A, B, C$ ) that lasted 11 months before intracranial progression (Figure $3 D$ ). Plasma circulating tumor DNA (ctDNA) genomic analysis by NGS revealed the known KIF5B-ALK fusion (22.35\% allele frequency) and an $A L K$ exon $23 \mathrm{~L} 1196 \mathrm{M}$ missense mutation $(0.12 \%$ allele frequency) (Figure 4$)$ after progression. Preclinical data and clinical studies indicated that the ALK L1196M mutation was sensitive to the secondgeneration inhibitors ceritinib or brigatinib (12). Then, $450 \mathrm{mg}$ ceritinib once daily was prescribed, which led to a partial radiographic response with regression of brain lesions (Figure $5 A, B$ ). The response was maintained for 9 months, and the patient continues to undergo follow-up with no significant drug related adverse reactions were found.

All procedures performed in studies involving human participants were in accordance with the ethical standards of the institutional and/or national research committee(s) and the Helsinki Declaration (as revised in 2013). Written informed consent was obtained from the patient.

\section{Discussion}

$A L K$ encodes anaplastic lymphoma kinase, which is associated with cell survival, angiogenesis, and proliferation and is frequently involved in chromosomal translocations, resulting in fusion genes with different partners. KIF5B is a rare partner for $A L K$, and the KIF5B$A L K$ variant accounts for approximately $0.4 \%$ of fusion partners (1 of 266 tumors) (13).

It is necessary to evaluate the sensitivity of a rare $K I F 5 B$ $A L K$ to ALK-TKIs to provide a better understanding of ALK-TKIs applications. Takeuchi et al. (4) reported a lung adenocarcinoma patient harboring the KIF5B-ALK fusion where intron 24 of $K I F 5 B$ was ligated to intron 19 of $A L K$. Another variant of the KIF5B-ALK fusion was reported by Wong et al. (13), namely, KIF5B exon 15 fusion to $A L K$ exon 20 in a patient with primary lung adenocarcinoma. However, neither of the cases reported the sensitivity of KIF5B-ALK to ALK-TKIs. Shimizu et al. (5) reported a case of LCNEC with KIF5B exon 17 fusion to $A L K$ exon 20. The patient was administered crizotinib for 10 months until presenting with multiple metastases in the brain. Although several KIF5B-ALK fusions with different breakpoints have been reported, the sensitivity of other rare fusion variants to ALK inhibitors remains unknown. KIF5B-ALK contains the same tyrosine kinase domain as $E M L 4-A L K$, and it is possible that patients with the KIF5B-ALK fusion may also respond well to ALK inhibitors (14). However, this hypothesis should be assessed in more cases and 


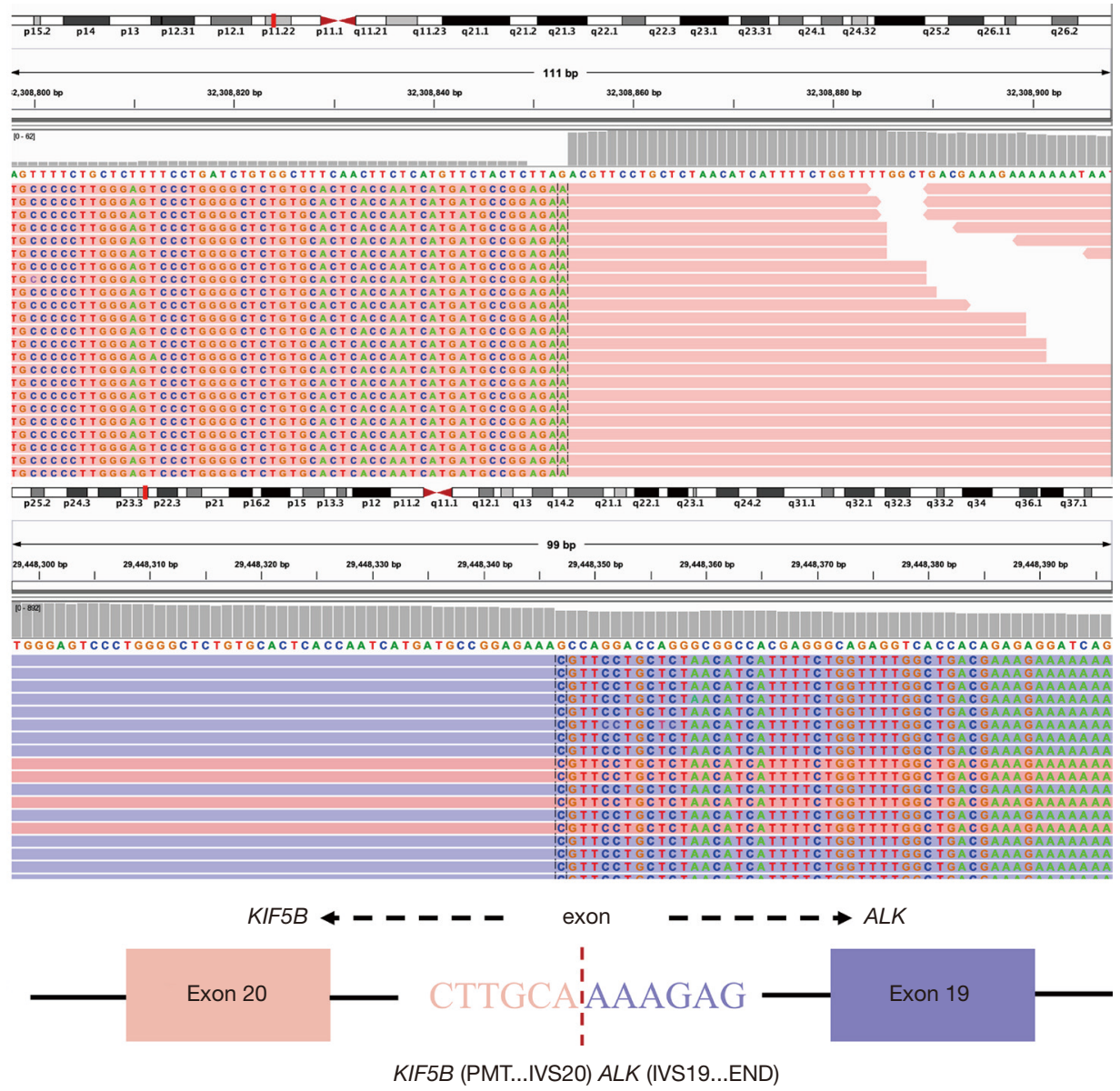

Figure 4 The rare kinesin family member $5 \mathrm{~B}(K I F 5 B)$-anaplastic lymphoma kinase $(A L K)$ fusion variant and sequencing reads of $A L K$ and KIF $5 B$ are presented using Integrative Genomics Viewer.
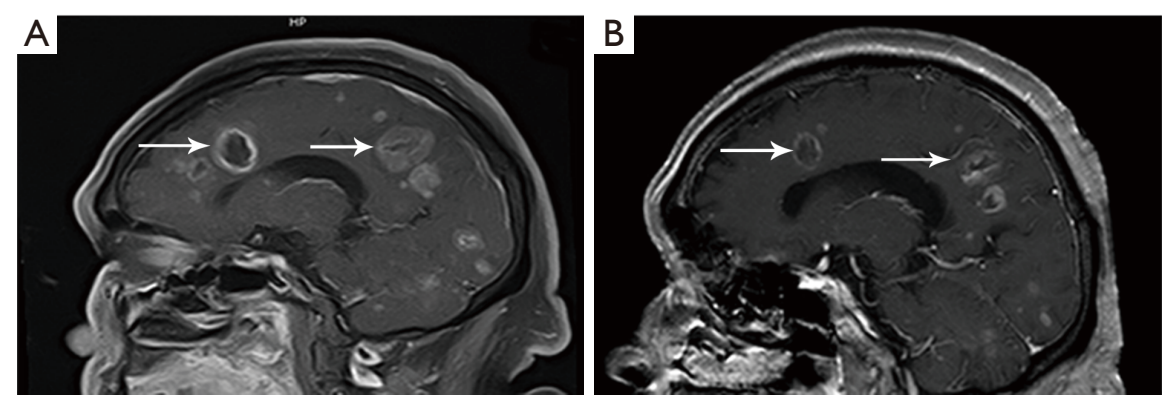

Figure 5 Dynamic magnetic resonance imaging (MRI) scan of brain lesions and the location of mass marked with white arrow. (A,B) Follow-up MRI scan after 2 months of ceritinib therapy $(3.2 \mathrm{~cm} \times 2.7 \mathrm{~cm})$ and after 5 months of ceritinib therapy $(1.7 \mathrm{~cm} \times 1.6 \mathrm{~cm})$.

studies. In our case, the patient with lung adenocarcinoma harbored another rare fusion variant in which intron 20 of $K I F 5 B$ was ligated to intron 20 of $A L K$. After crizotinib was administered, the patients achieved progression-free survival (PFS) for 11 months. This is the first report to demonstrate that $K I F 5 B-A L K(\mathrm{~K} 20: \mathrm{A} 20)$ is a fusion variant that is sensitive to crizotinib. Future studies should assess whether other $K I F 5 B-A L K$ fusion variants with different 
breakpoints also respond to crizotinib.

Although the effects of crizotinib are initially substantial, patients inevitably develop resistance (15). Second and third ALK-TKIs play different roles in inhibiting secondary mutations in the treatment of drug resistance related to the use of other ALK-TKIs (12). ALK kinase domain mutations were noted in $66.7 \%$ of patients after treatment with crizotinib, and mutations that confer resistance, including G1202R, G1269A, I1171T, L1196M, C1156Y and $\mathrm{F} 1245 \mathrm{~V}$, were investigated (16). L1196M is a common secondary mutation in NSCLC and a point mutation in the $A L K$ tyrosine kinase region that can dramatically alter protein conformations. This mutation plays an important role in sterically blocking the binding of crizotinib, which also affected the flexibility of loops L1 and L2 in ALK and induced the conformational drift of ALK (17). The L1196M mutation is located in the protein kinase domain of the ALK protein (UniProt.org: Q9UM73) and similarly demonstrated to be a resistance mutation in the crizotinib-resistant patient in our report. However, optimal sequential administration of ALK inhibitors after resistance to crizotinib in patients harboring the L1196M missense mutation has not been elucidated, especially patients with brain metastasis. Crizotinib does not easily penetrate the blood-brain barrier. However, second-generation ALKTKIs effectively prevent intracranial progression $(18,19)$. A preclinical evaluation demonstrated that ceritinib can overcome crizotinib resistance, particularly inhibiting ALK harboring L1196M, but without PFS data (20). Fortunately, the patient reported in our case achieved a long PFS of 9 months with the administration of ceritinib with ongoing follow-up.

In conclusion, this case presented a rare crizotinibsensitive KIF5B-ALK (K20:A20) fusion and a resistance mutation after disease progression, highlighting the importance of dynamic genomic analysis on ALK-TKIs treatments. Similarly, analysis of the mechanisms of postprogression is extremely valuable. These analyses not only facilitate a better understanding of the molecular mechanisms of resistance and predictions of clinical outcomes but also assist clinicians in personalizing ALKtargeted strategies.

\section{Acknowledgments}

We thank all medical staffs for their essential assistance with collection of information regarding this case.

Funding: This work was supported by the National
Science Foundation of China (82072598, 81871890, and 91859203), the National Major Science and Technology Project of China (2017ZX10103004-012), the National Key Development Plan for Precision Medicine Research of China (2017YFC0910004), the Science and Technology Program of Sichuan, China (2020YFS0572) and the Major Science and Technology Innovation Project of Chengdu City, China (2020-YF08-00080-GX).

\section{Footnote}

Reporting Checklist: The authors have completed the CARE reporting checklist. Available at http://dx.doi.org/10.21037/ apm-20-2081

Conflicts of Interest: All authors have completed the ICMJE uniform disclosure form (available at http://dx.doi. org/10.21037/apm-20-2081). The authors have no conflicts of interest to declare.

Ethical Statement: The authors are accountable for all aspects of the work in ensuring that questions related to the accuracy or integrity of any part of the work are appropriately investigated and resolved. All procedures in studies involving human participants were performed in accordance with the ethical standards of the institutional and/or national research committee(s) and with the Helsinki Declaration (as revised in 2013). Written informed consent was obtained from the patient.

Open Access Statement: This is an Open Access article distributed in accordance with the Creative Commons Attribution-NonCommercial-NoDerivs 4.0 International License (CC BY-NC-ND 4.0), which permits the noncommercial replication and distribution of the article with the strict proviso that no changes or edits are made and the original work is properly cited (including links to both the formal publication through the relevant DOI and the license). See: https://creativecommons.org/licenses/by-nc-nd/4.0/.

\section{References}

1. Hou X, Xu H, Chen L. SRBD1-ALK, a Novel ALK Fusion Gene Identified in an Adenocarcinoma Patient by Next-Generation Sequencing. J Thorac Oncol 2019;14:e72-3.

2. Tian Q, Deng WJ, Li ZW. Identification of a novel crizotinib-sensitive BCL11A-ALK gene fusion in 
a nonsmall cell lung cancer patient. Eur Respir J 2017;49:1602149.

3. Shan L, Jiang P, Xu F, et al. BIRC6-ALK, a Novel Fusion Gene in ALK Break-Apart FISH-Negative Lung Adenocarcinoma, Responds to Crizotinib. J Thorac Oncol 2015;10:e37-9.

4. Takeuchi K, Choi YL, Togashi Y, et al. KIF5BALK, a novel fusion oncokinase identified by an immunohistochemistry-based diagnostic system for ALKpositive lung cancer. Clin Cancer Res 2009;15:3143-9.

5. Shimizu N, Akashi Y, Fujii T, et al. Use of ALK Immunohistochemistry for Optimal Therapeutic Strategy of Pulmonary Large-cell Neuroendocrine Carcinoma and Identification of a Novel KIF5B-ALK Fusion Oncokinase. Anticancer Res 2019;39:413-20.

6. Li Y, Zhang T, Zhang J, et al. Response to crizotinib in advanced ALK -rearranged non-small cell lung cancers with different ALK -fusion variants. Lung Cancer 2018;118:128-33.

7. Ettinger DS, Aisner DL, Wood DE, et al. NCCN Guidelines Insights: Non-Small Cell Lung Cancer, Version 5.2018. J Natl Compr Canc Netw 2018;16:807-21.

8. Guan H, Sheng Y, Guo W, et al. Cost-Effectiveness of Alectinib for Patients with Untreated ALK-Positive Non-Small Cell Lung Cancer in China. Adv Ther 2019;36:1114-25.

9. McDermott U, Iafrate AJ, Gray NS, et al. Genomic alterations of anaplastic lymphoma kinase may sensitize tumors to anaplastic lymphoma kinase inhibitors. Cancer Res 2008;68:3389-95.

10. Tiseo M, Gelsomino F, Bartolotti M, et al. Anaplastic lymphoma kinase as a new target for the treatment of non-small-cell lung cancer. Expert Rev Anticancer Ther 2011;11:1677-87.

11. Riley DS, Barber MS, Kienle GS, et al. CARE guidelines for case reports: explanation and elaboration document. J

Cite this article as: Zeng $\mathrm{H}$, Liu $\mathrm{Y}$, Wang W, Tang $\mathrm{Y}$, Tian $\mathrm{P}, \mathrm{Li}$ W. A rare $K I F 5 B-A L K$ fusion variant in a lung adenocarcinoma patient who responded to crizotinib and acquired the $A L K L 1196 M$ mutation after resistance: a case report. Ann Palliat Med 2021;10(7):8352-8357. doi: 10.21037/apm20-2081
Clin Epidemiol 2017;89:218-35.

12. Gainor JF, Dardaei L, Yoda S, et al. Molecular Mechanisms of Resistance to First- and Second-Generation ALK Inhibitors in ALK-Rearranged Lung Cancer. Cancer Discov 2016;6:1118-33.

13. Wong DW, Leung EL, Wong SK, et al. A novel KIF5BALK variant in nonsmall cell lung cancer. Cancer 2011;117:2709-18.

14. Kwak EL, Bang YJ, Camidge DR, et al. Anaplastic lymphoma kinase inhibition in non-small-cell lung cancer. N Engl J Med 2010;363:1693-703.

15. Camidge DR, Bang YJ, Kwak EL, et al. Activity and safety of crizotinib in patients with ALK-positive non-small-cell lung cancer: updated results from a phase 1 study. Lancet Oncol 2012;13:1011-9.

16. Chen W, Guo X, Zhang C, et al. Discovery of 2-aminopyridines bearing a pyridone moiety as potent ALK inhibitors to overcome the crizotinib-resistant mutants. Eur J Med Chem 2019;183:111734.

17. Chen J, Wang J, Zhu W. Mutation L1196M-induced conformational changes and the drug resistant mechanism of anaplastic lymphoma kinase studied by free energy perturbation and umbrella sampling. Phys Chem Chem Phys 2017;19:30239-48.

18. Hayashi N, Fujita A, Saikai T, et al. Large Cell Neuroendocrine Carcinoma Harboring an Anaplastic Lymphoma Kinase (ALK) Rearrangement with Response to Alectinib. Intern Med 2018;57:713-6.

19. Kimura H, Nakajima T, Takeuchi K, et al. ALK fusion gene positive lung cancer and 3 cases treated with an inhibitor for ALK kinase activity. Lung Cancer 2012;75:66-72.

20. Friboulet L, Li N, Katayama R, et al. The ALK inhibitor ceritinib overcomes crizotinib resistance in non-small cell lung cancer. Cancer Discov 2014;4:662-73. 